\title{
A survey of depression and anxiety disorders in urban and rural Suriname
}

\author{
Raj Jadnanansing ${ }^{1 *}$, Edwin de Beurs ${ }^{2,3}$, Kajal Etwaroo ${ }^{1}$, Matthijs Blankers ${ }^{2}$, Rudi Dwarkasing ${ }^{4}$, Jaap Peen², \\ Vincent Lumsden ${ }^{4}$, Robbert Bipat ${ }^{5}$ and Jack Dekker ${ }^{2,6}$
}

\begin{abstract}
Background: Suriname is a Low-middle income country consisting of diverse population groups. Epidemiological studies concerning mental disorders like depression and anxiety had not been conducted until 2015. The treatment gap for mental disorders in Low and middle-income countries (LMICS) may reach $76-80 \%$ as treatment is not always readily available. In this study, we estimate and compare the prevalence of potential cases of depression and anxiety, as well as the size of the treatment gap in a rural (Nickerie) and urban (Paramaribo) region of Suriname, a lower middle-income country.
\end{abstract}

Methods: Subjects were selected by a specific sampling method of the national census bureau. The Center for Epidemiological Studies-Depression (CES-D) was used to assess depression. Generalized anxiety disorder was assessed with the Generalized Anxiety Disorder 7 (GAD-7) and The Agoraphobic Cognitions Questionnaire (ACQ), the Body Sensations Questionnaire (BSQ) were used to assess Panic disorder. The treatment gap was calculated by estimating the percentage of subjects with depression or anxiety that did not seek out professional help.

Results: About 18\% of the respondents from Nickerie and 16\% from Paramaribo were at risk of depression and the established cut-off values of the instruments used indicate that about 3-4\% in both regions may suffer from Generalized Anxiety Disorder. Women in both samples were most at risk of high anxiety about body sensations and maladaptive thoughts about panic. The treatment gap varies between 78 and 100\% for the two disorders.

Conclusions: A high depression rate has been found in both areas, especially among young females. In addition, a high treatment gap is noted which insinuates that more therapeutic strategies are required to tackle depression and anxiety in Suriname.

Keywords: Depression, Anxiety, Treatment gap, Urban, Rural

\section{Introduction}

Depression is a common psychiatric disorder that has a negative effect on how an individual feels, thinks and behaves (The American Psychiatric Association, 2013). The Diagnostic and Statistical Manual of Mental Disorders (DSM-5) [1] indicates that the core symptoms

*Correspondence: raj.jadnanansing@pcs.sr; rajad5@yahoo.com

${ }^{1}$ Center for Psychiatry in Suriname and Faculty of Social Science, Anton

de Kom University of Suriname, Letitia Vriesdelaan 1 - 3, Paramaribo,

Suriname

Full list of author information is available at the end of the article of depression are a gloomy mood and a loss of interest and pleasure. The disorder usually presents as a lack of energy, disturbed sleep or appetite, low self-esteem [2] and aversion to activity, or apathy, which may affect a person's thoughts, feelings, behaviour and sense of wellbeing [3]. Biological, environmental, and personal vulnerabilities interact to contribute to the development of depression, [4] which - when chronic - substantially impairs an individual's ability to fulfil of day-to-day responsibilities, possibly even resulting in suicide [2]. The 
12-month prevalence of major depression (DSM-IV) is thought to be between 5 and $6 \%$ worldwide [5].

About $85 \%$ of patients with depression also experience significant anxiety, while comorbid depression occurs in up to $90 \%$ of patients with anxiety disorders [6, 7]. Anxiety becomes problematic when it affects normal daily functioning. According to the DSM-5 [1], the condition shares features of excessive fear and anxiety, and related behavioural disturbances. An anxiety disorder is defined by excessive worry, hyperarousal and fear that is counterproductive and debilitating [8]. Both depression and anxiety are commonly linked to suicide $[9,10]$.

Anxiety and depressive disorders and symptoms significantly impair functioning in a number of areas including work, social life and health $[11,12]$. In fact, the quality of life among depressed adults is more impaired than that of adults with diabetes, hypertension and chronic lung disease [13]. Similarly, anxiety has also been associated with a number of negative outcomes, including decreased work productivity, impaired work, family and social functioning, physical disability and even mortality [14-16].

On average, countries spend $21.7 \%$ of their health budgets on mental health, even though $14 \%$ of years lived with disability globally are known to be caused by depression and anxiety [17]. Depression is the most common mental illness, which affects more than 300 million people globally. Depression significantly contributes to the overall global burden of disease and is the single largest contributor to global disability $[18,19]$.

Depression and anxiety rates are generally higher in urban areas than in rural areas but there may be country-specific variations [17]. More than $50 \%$ of the global population lives in cities. This rise in urbanisation means that more people are exposed to risk factors associated with the social or physical environment in urban settings. This contributes to increasing stress, which is in turn negatively associated with mental health problems [20]. A systematic review [21] found that the annual prevalence of any given anxiety disorder varied between 2.4 and $29.8 \%$ across 44 countries (87 studies), and that the prevalence was higher in urban areas than in rural areas. Depending on severity, these disorders are managed with low-dose anti-depressants like serotonin reuptake inhibitors or anxiolytics like benzodiazepines [22]. However, psychological treatment and support is preferred for efficacy and price reasons $[23,24]$ and eHealth interventions using this approach have produced small but positive effects on symptom reduction [25]. Psychological treatment is not readily available in lower middle income countries (LMICs) and the treatment gap for mental disorders may consequently reach $76-80 \%$ in these countries [26]. Depression and anxiety make a significant contribution to the burden of disease and disability in low and middle income countries [27], thus an epidemiological study of depression and anxiety in a Low and Middle Income country is of great importance. In addition recent data on contributing social determinants for the risk of these disorders is scant and only a few recent studies are available. A systematic review of studies carried out in the Caribbean concluded in 2017 that the risk for depression follows the global trend [28]. A study among the diaspora in the USA found that they showed a lower risk of developing anxiety, but that on the other hand the disorder was more severe when developed [29]. Hence it is important to continuously determine the risk of developing these disorders and assessing their treatment gap.

The current study focuses on the prevalence of possible cases of depression and anxiety in a rural and an urban area in Suriname, a lower middle income country in South America. In this study we screen and identify people with a high risk of depression and anxiety, by screening the symptoms with the use of validated screening instruments. In addition to the indigenous people, the population consists of groups with different origins that can be traced back to Suriname's plantation history: Maroons (21.7\%), Creoles (15.7\%), West Indians (27.4\%), Javanese (13.7\%), mixed race people $(13.4 \%)$, people with another ethnicity $(7.6 \%)$ and a small group of unknown ethnicities (0.6\%) [30]. The capital of Suriname is the urban and generally industrial district, Paramaribo. Its rural counterpart is Nickerie, which is a mostly agricultural area. Several studies have found that the suicide rate in Suriname is higher than average but a possible relation with depression and/or anxiety has yet to be established [22]. No epidemiological studies of the depression and anxiety rates in the Surinamese population had been conducted prior to our study in 2015.

On the basis of major population surveys around the world, we expected higher depression and anxiety rates in the urban setting of Paramaribo than in the rural region of Nickerie. Gender differences for depression are not as apparent in rural contexts and they may even be absent in some societies [23, 24]. We will therefore compare gender differences in both the urban and rural contexts covered by this study.

The present study compared the prevalences of depression and anxiety in a rural and an urban area in Suriname and the associated factors. Nickerie and Paramaribo were selected for this study because of the urban and rural characteristics of the districts. Paramaribo is the only really urban area of Suriname and the distance between Paramaribo and Nickerie ensures that there is little to no urban influence on the latter. In addition, the treatment gap (respondents at risk but not receiving treatment) was also assessed in both areas. 


\section{Methods}

\section{Study design}

In 2015 and 2016, we performed a large-scale survey of mental disorders and alcohol use disorder in the populations of Nickerie and Paramaribo, the first of its kind to be conducted in this country. The Centre for Psychiatry in Suriname (PCS) in Paramaribo initiated this largescale survey in 2014 in collaboration with Arkin (a Dutch mental health service in Amsterdam) and the VU University in Amsterdam.

The collaboration resulted in a twinning project between the Surinamese PCS and Arkin, which funded the study [25]. For the purposes of the survey two districts were selected from the total of ten in the country: Paramaribo, Wanica, Nickerie, Coronie, Saramacca, Commewijne, Para, Marowijne, Brokopondo and Sipaliwini.

The results relating to alcohol and other substance use have been described in a separate paper [26]. The present paper looks at the results for depression and anxiety.

Suriname, a former Dutch colony, gained its independence and became a republic in 1975. In addition to the official language (Dutch), almost all inhabitants speak another language depending on their ancestral origins.

The country currently has a population of approximately 600,000 [30]. In addition, almost 400,000 people from at least three generations live in diaspora in the Netherlands. The result is intensive bilateral travel between these two countries.

\section{Participants/respondents}

The respondents were recruited in the two areas using a specific sampling method using a large sample of $10 \%$ of all households in each participating resort, which are smaller population units in each district. The sampling method has been developed by the Algemeen Bureau voor de Statistiek of Suriname (ABS) (General Bureau of Statistics), where researchers and others can obtain adequate statistics for large scale research. This is the most common way for researchers in Suriname to obtain a representative population for their research. The ABS selected the addresses of the respondents aged 16-65 so as to ensure a balanced geographical distribution. The addresses where people no longer lived or that were abandoned were skipped and the interviewers then continued to the addresses of the houses to the right. This scenario had been taken into account before the field research began and, to ensure enough households were recruited, ABS had also supplied additional addresses. The final samples consisted of 1837 households for Paramaribo and 1026 for Nickerie. This ratio reflects the relative number of households in the two areas.
In the 23rd and the 42nd week of 2016, interviewers approached approximately 1100 and 2000 participants in Nickerie and Paramaribo, respectively. The respondents were required to give both written and oral consent for the study because not all of them were literate. The respondents who ultimately agreed to participate in the study were asked to complete a confidentiality form in order to safeguard their privacy. The interview was conducted in situ in a quiet location where the interviewer explained the aim of the study and asked the questions in the respondent's preferred language. The respondents were given enough time to complete the questionnaire and all interviews were collected and submitted electronically. Government authorities and the district police made protection arrangements for the interviewers.

,After the selection, the respondents were required to give both written and verbal consent for the study because not all of them were literate. The respondents who ultimately agreed to participate in the study were asked to complete a confidentiality form in order to protect their privacy during this study. Interviews were conducted in a quiet place where the interviewer explained the aim of the study and the questions in the language referred by the respondents. Each respondent was given enough time to complete the questionnaire and all interviews were collected and submitted electronically. The interviews that could not be conducted and submitted electronically immediately, mostly due to network access issues, were conducted in writing and then transcribed and submitted electronically by the interviewer.

During this pilot study, the district commissioners (DCs), board supervisors and the police force provided assistance with the practicalities of collecting data. The DCs were informed about the purpose and design of the study beforehand, the police force organised physical protection for the interviewers and the board supervisors accompanied the interviewers as they knew the places and respondents well.

\section{Selection and training of interviewers}

Before main data collection began in Nickerie and Paramaribo, a small pilot study with thirty respondents was completed in the regional health centre to validate the research tool. After each day of data collection in this pilot study, the group evaluated the difficulties that had been encountered and questionnaires with invalid or missing information were put aside immediately. The pilot study showed that it was necessary to translate the questionnaire into Hindustani, English and Surinamese. Although Dutch is the main language in both Nickerie and Paramaribo, the multi-cultural society of Suriname means that the inhabitants speak different languages and so the questionnaires sometimes had to be translated 
to make completion easier for respondents who spoke another language.

Another conclusion to emerge from the pilot study was that the students working as interviewers needed professional training. The students were interviewed individually by a psychiatrist, a researcher and a psychologist before being selected for training. Students with an academic background in psychology, with experience in similar interview work and students who spoke more than one language were preferred.

The training began after the completion of this selection procedure. It was delivered by experienced psychologists and psychiatrists and consisted of different components. Firstly, all the important terms such as depression, panic disorder and anxiety were discussed. Secondly, the students were given instructions about how to conduct and score the questionnaire.

In the last few days of the training, different dialects were practised with the students to prepare them for all types of situations in the field. The training lasted two weeks.

\section{Study size}

Nickerie has a population of 34,233 and the final sample in Nickerie was 1026. Paramaribo has a population of 240,924 and the final sample was 1837. With the population size of both Nickerie and Paramaribo, an alpha of 0.05 , and an error margin of $3 \%$, with the aid of an online calculator (https://www.stat.ubc.ca/ rolling/stats/size/ $\mathrm{n} 2 . \mathrm{html}$ ) it was determined that the sample size in Nickerie should be 1035 and in Paramaribo 1065. We oversampled to compensate for missing data. All the selected respondents were interviewed. If they were not available initially, the interviewer returned at another time to ensure that the questionnaire was completed.

\section{Assessment/Instruments}

Depression: the CESD The Center for Epidemiological Studies Depression (CES-D) was designed to measure the level of depressive symptomatology in the general population [27]. Twenty items enquire about the frequency of symptoms in the past week, with response options ranging from 0 "Not at all" to 3 "Nearly every day". The total sum score ranges from 0 to 60 and the cut-off point typically recommended for depression cases is 16 [31].

Sensitivity for major depression varies between 60 and 99\% and specificity is between 73 and $94 \%$ for this cut-off point $[32,33]$, which we used in this study.

Anxiety Two aspects of common anxiety were measured: generalized anxiety and excessive worry, and panic disorder. Generalized anxiety and worry was measured with the GAD-7 [34].

The GAD consists of seven items describing feelings such as "Trouble relaxing", "Feeling nervous, anxious or on edge" and "Feeling afraid that something awful might happen". Items are scored on a 4-point Likert scale $(0=$ not at all to $3=$ nearly every day $)$, resulting in a theoretical range in scores of 0 to 21 . The GAD-7 has good reliability and good criteria, construct, factorial and procedural validity [34]. The cut-off point to establish a GAD is 16 or higher with optimal sensitivity (89\%) and specificity $(82 \%)$ [34]. As stated above, this cut-off was also used in this study.

Fear of fear was measured with the Agoraphobic Cognitions Questionnaire (ACQ) [35] and the Body Sensations Questionnaire (BSQ) [35]. The ACQ was devised to measure maladaptive thoughts about the possible consequences of panic (the cognitive aspect). Respondents rate the frequency of these thoughts when feeling anxious or frightened in fourteen items. Each item is rated on a 5-point Likert scale ranging from 1 (thought never occurs) to (thought always occurs). We used the total score (ACQ_TOT) in this study.

The scale discriminates well between patients and normal controls: Chambless et al. (1984) reported a mean score of $2.32(\mathrm{SD}=0.66)$ for outpatients with agoraphobia, and $1.60(\mathrm{SD}=0.46)$ for a community sample. The Dutch version of the ACQ was psychometrically evaluated by Arrindell (1993): it proved to be reliable (internal consistency Cronbach's a $>.82$ for the ACQ) and testretest reliability was good (Pearson PMC $r>0.79$ ) [36]. A Dutch study [37] classified male respondents with a total score of more than 1.94 and female respondents with a total score of more than 1.86 [37] as highly anxious. We also use these cut-off points in this study.

The BSQ measures fear of the bodily sensations which are commonly experienced during anxiety and panic attacks. The BSQ consists of seventeen items, each of which describes a physical symptom such as dizziness, palpitations or breathlessness.

Items are rated on a five-point scale describing the level of anxiety they provoke ranging from 1 (not at all) to 5 (extreme). Chambless (1984) reported a mean score of $3.05(\mathrm{SD}=0.86)$ for outpatients with agoraphobia and $1.80(\mathrm{SD}=0.59)$ for a community sample.

The Dutch version of the BSQ was psychometrically evaluated by Arrindell (1993) and found to be 
reliable (internal consistency Cronbach's a $>.89$ for BSQ) and test-retest reliability was good (Pearson PMC $r>0.79)$. For this study, we have used cut-off points from a Dutch study (Bouman, 1995) in which male respondents with a total score of more than 2.47 and female respondents with a total score of more than 2.40 were classified as being highly anxious about body sensations.

\section{Treatment gap}

After respondents completed the questionnaires on depression and anxiety, they were asked whether they had sought help from a General Practitioner or health professional for the reported psychological complaints. The treatment gap was calculated by determining the percentage of subjects with a depression or anxiety who did not seek help for related physical or mental disorders.
Statistics Differences between socio-demographic characteristics in Paramaribo and Nickerie, and between respondents with or without risk of depression or anxiety, were compared using Chi-Squared $\left(x^{2}\right)$ testing when confronted with categorical variables. All statistical analyses were conducted with SPSS (version 26; IBM; NY).

The quality assurance for the analyses was conducted with SPSS and Graphpad for Prism version 8.3. Data are presented as means $(95 \% \mathrm{CI})$ unless noted otherwise.

\section{Results}

A total of 1026 participants participated in the study in the Nickerie district. Of these, 593 were female and 433 were male. In Paramaribo, 1065 women and 772 men participated, a total of 1837 respondents. The entire sample for this study therefore consisted of 2863 participants.

Table 1 An overview of risk of depression based on demographic characteristics of both samples

\begin{tabular}{|c|c|c|c|c|c|}
\hline \multirow[t]{2}{*}{ Variable } & & Nickerie & $P$ & Paramaribo & $P$ \\
\hline & & \multicolumn{2}{|l|}{$\begin{array}{l}\text { Possible cases of } \\
\text { depression }\end{array}$} & \multicolumn{2}{|l|}{$\begin{array}{l}\text { Possible cases of } \\
\text { depression }\end{array}$} \\
\hline \multirow[t]{2}{*}{ Age } & $<40$ & 74 (15.7\%) & 0.141 & 160 (17.4\%) & $0.032^{*}$ \\
\hline & $>40$ & 115 (20.9\%) & & $136(14.8 \%)$ & \\
\hline \multirow[t]{2}{*}{ Gender } & Male & $86(15.8 \%)$ & $0.000^{*}$ & $89(11.5 \%)$ & $0.000^{*}$ \\
\hline & Female & $121(20.5 \%)$ & & 207 (19.4\%) & \\
\hline \multirow[t]{3}{*}{ Education } & Low & $141(21.7 \%)$ & $0.001^{*}$ & 188 (20.1\%) & $0.002^{*}$ \\
\hline & Secondary & 46 (12.9\%) & & $58(12.4 \%)$ & \\
\hline & High & $1(7.7 \%)$ & & 18 (13.1\%) & \\
\hline \multirow[t]{6}{*}{ Marital Status } & Single & 39 (14.3\%) & $0.000^{*}$ & 149 (17\%) & $0.000^{*}$ \\
\hline & Married & 82 (16.8\%) & & $54(11.2 \%)$ & \\
\hline & Widowed & 15 (37.7\%) & & 16 (25.8\%) & \\
\hline & Divorced & 23 (39.7\%) & & 19 (25.3\%) & \\
\hline & Concubinage & 27 (18.4\%) & & $46(15.5 \%)$ & \\
\hline & Long-distance relationship & $3(30 \%)$ & & $12(27.9 \%)$ & \\
\hline \multirow[t]{6}{*}{ Ethnic background } & West Indians & $131(20.7 \%)$ & $0.000^{*}$ & $82(19.3 \%)$ & $0.045^{*}$ \\
\hline & Creole & $14(14.9 \%)$ & & $78(14.7 \%)$ & \\
\hline & Maroon & $0(0 \%)$ & & $53(24.5 \%)$ & \\
\hline & Javanese & $24(13.4 \%)$ & & $17(19.1 \%)$ & \\
\hline & Mixed & $11(14.1 \%)$ & & $54(13.7 \%)$ & \\
\hline & Other & $9(31 \%)$ & & $12(14.3 \%)$ & \\
\hline \multirow[t]{7}{*}{ Daily activity } & Student/going to school & $8(8.5 \%)$ & $0.000^{*}$ & $46(19.7 \%)$ & $0.033^{*}$ \\
\hline & Working part-time & $15(22.1 \%)$ & & $18(17.3 \%)$ & \\
\hline & Working full-time & $56(16.8 \%)$ & & $115(12.2 \%)$ & \\
\hline & Unemployed/jobseeker & $25(25 \%)$ & & $35(31.5 \%)$ & \\
\hline & Housewife/Houseman & $71(21.7 \%)$ & & $60(21.9 \%)$ & \\
\hline & Handyman & $6(13.6 \%)$ & & $8(21.2 \%)$ & \\
\hline & Retired & $6(14 \%)$ & & $14(10.2 \%)$ & \\
\hline
\end{tabular}


The response rate was almost $100 \%$ with the exception of a few missing respondents.

\section{Representativeness}

Paramaribo has a population of 140,679: 51\% female and $49 \%$ male, with $53 \%$ being younger than 40 years old. Nickerie has a population of 71,867: $47 \%$ female and $53 \%$ male, with $52 \%$ being younger than 40 years old.

Both samples included a significantly higher number of elderly women and a significant underrepresentation of younger men: $58 \%$ women $\left(\mathrm{x}^{2}=35.6 ; \mathrm{df}=1 ; p=0.000\right)$ in Paramaribo and $59 \%$ in Nickerie $\left(x^{2}=46.9\right.$; $\mathrm{df}=1 ; p=0.000), 54 \%$ of whom were older than 40 years $\left(\mathrm{x}^{2}=13.3 ; \mathrm{df}=1 ; p=0.000\right)$.

\section{Demographics of the respondents}

As stated above, the study sample consisted of 2863 people $(N=2863)$. In Nickerie, there were 593 female participants and 433 men, a total of 1026.
Most respondents from both Paramaribo (60.8\%) and Nickerie (63.8\%) had a low education level and worked full time (Paramaribo: $51.1 \%$ and Nickerie: 33\%). The majority of the respondents in Paramaribo were single $(47.7 \%)$ and the majority of the respondents from Nickerie were married (48.2\%). Most respondents in Paramaribo (28.9\%) consisted of Creole people and most respondents in Nickerie consisted of West Indians (61.9\%).

Table 1 shows the risk for depression in both samples. The risk of depression in Nickerie is $18 \%$ and approximately $16 \%$ in Paramaribo. There are significant differences between the two samples in terms of gender, education level, marital status, ethnic background and daily activity. Risk factors include: female, low education, being widowed or divorced, and long-distance relationships. Furthermore, the Maroon subjects in the Paramaribo sample are most at risk. In the Nickerie sample, the West Indian, Javanese or different (those who chose 'different' as their ethnic background) subjects were most at risk.

Table 2 An overview of the risk of anxiety (according to the GAD-7) based on demographic characteristics of both samples

\begin{tabular}{|c|c|c|c|c|c|}
\hline Variable & & $\begin{array}{l}\text { Nickerie } \\
\text { Risk anxiety }\end{array}$ & $P$ & $\begin{array}{l}\text { Paramaribo } \\
\text { Risk anxiety }\end{array}$ & $P$ \\
\hline \multirow[t]{2}{*}{ Age } & $<40$ & $12(2.6 \%)$ & 0.127 & $27(2.9 \%)$ & $0.053^{*}$ \\
\hline & $>40$ & $27(4.9 \%)$ & & $39(4.3 \%)$ & \\
\hline \multirow[t]{2}{*}{ Gender } & Male & $7(1.6 \%)$ & $0.049^{*}$ & $20(2.6 \%)$ & $0.002^{*}$ \\
\hline & Female & $32(5.4 \%)$ & & $46(4.3 \%)$ & \\
\hline \multirow[t]{3}{*}{ Education } & Low & $32(4.9 \%)$ & $0.012^{*}$ & $46(4.9 \%)$ & $0.026^{*}$ \\
\hline & Secondary & $6(1.7 \%)$ & & $10(2.1 \%)$ & \\
\hline & High & $0(0 \%)$ & & $2(1.5 \%)$ & \\
\hline \multirow[t]{6}{*}{ Marital Status } & Single & $7(2.6 \%)$ & 0.056 & $24(2.7 \%)$ & 0.08 \\
\hline & Married & $17(3.4 \%)$ & & $19(3.9 \%)$ & \\
\hline & Widowed & $4(9.5 \%)$ & & $4(6.5 \%)$ & \\
\hline & Divorced & $5(8.6 \%)$ & & $7(9.3 \%)$ & \\
\hline & Concubinage & $5(3.4 \%)$ & & $10(3.4 \%)$ & \\
\hline & Long-distance relationship & $1(10 \%)$ & & $2(4.7 \%)$ & \\
\hline \multirow[t]{6}{*}{ Ethnic background } & West Indians & $28(4.4 \%)$ & $0.037^{*}$ & $26(6.1 \%)$ & 0.527 \\
\hline & Creole & $3(3.2 \%)$ & & $13(2.4 \%)$ & \\
\hline & Maroons & $0(0 \%)$ & & $5(2.3 \%)$ & \\
\hline & Javanese & $7(3.9 \%)$ & & $5(2.7 \%)$ & \\
\hline & Mixed & $0(0 \%)$ & & $13(3.3 \%)$ & \\
\hline & Other & $1(3.4 \%)$ & & $4(4.8 \%)$ & \\
\hline \multirow[t]{7}{*}{ Daily activity } & Student/going to school & $3(3.2 \%)$ & $0.000^{*}$ & $9(3.8 \%)$ & $0.019^{*}$ \\
\hline & Working part-time & $0(0 \%)$ & & $4(3.8 \%)$ & \\
\hline & Working full-time & $9(2.7 \%)$ & & $21(2.2 \%)$ & \\
\hline & Unemployed/jobseeker & $5(5 \%)$ & & $10(9 \%)$ & \\
\hline & Housewife/Houseman & $22(6.7 \%)$ & & $20(7.3 \%)$ & \\
\hline & Handyman & $0(0 \%)$ & & $1(2.6 \%)$ & \\
\hline & Retired & $0(0 \%)$ & & $66(3.6 \%)$ & \\
\hline
\end{tabular}


The table also shows that age plays a role in Nickerie only: older respondents ( $>40$ years) in Nickerie are most likely to suffer from depression.

Table 2 shows that the two samples have an equal risk of developing an anxiety disorder. Approximately $3.8 \%$ of the respondents in Nickerie and approximately $3.6 \%$ in Paramaribo may have GAD. There are significant differences between the two samples in terms of gender, education and daily activity. In terms of gender differences, we saw a higher anxiety risk for women in both Nickerie (5.4\%) and Paramaribo (4.3\%). In both samples people with low education have the most anxiety risk as opposed to the other education levels. Significant risk factors for anxiety disorders in both samples are: female, housewife, low education, divorced or widowed and unemployment. In addition, the West Indian respondents in Paramaribo are most at risk of an anxiety disorder. It should also be noted that those who are older than 40 are more likely to develop anxiety disorders in both Paramaribo (39\%) and Nickerie (27\%).

Table 3 demonstrates that women in both samples are more at risk of high anxiety about body sensations (which was seen in approximately $19 \%$ of women and $10 \%$ of men). In the Nickerie sample, we found the highest risk among housewives (25\%). Generally the results show that women and housewife/houseman have a higher odd of getting depressed. $\mathrm{n}$ the Paramaribo sample, students, the unemployed and housewives had a high risk (ranging from 17 to 21\%). Furthermore, in the Paramaribo sample, the Maroons had the highest risk (24\%). Young people under forty in Paramaribo also have a high risk (18\%).

Table 4 shows that women in both samples were more at risk of maladaptive thoughts about panic (about 5 to $6 \%$ ) than the men (about 2\%). The highest risk in the Nickerie sample was seen in housewives (9\%) and in the Paramaribo sample in handymen (18\%).

Table 5 presents the treatment gaps for the various disorders. They vary between 78 and $100 \%$. The mean gap is about $90 \%$. There are no significant differences between the two areas.

Table 6 shows that there was no difference between the two regions with regard to the risk of the disorders.

Table 3 Overview of the relationship between demographics and risk of high anxiety about body sensations

\begin{tabular}{|c|c|c|c|c|c|c|c|}
\hline \multirow[t]{2}{*}{ Variable } & & \multicolumn{2}{|l|}{ Nickerie } & \multirow[t]{2}{*}{$P$} & \multicolumn{2}{|l|}{ Paramaribo } & \multirow[t]{2}{*}{$P$} \\
\hline & & Low & High & & Low & High & \\
\hline \multirow[t]{2}{*}{ Age } & $<40$ & 395 (84\%) & $75(16 \%)$ & $0.001^{*}$ & $760(82.5 \%)$ & $161(17.5 \%)$ & 0.943 \\
\hline & $>40$ & 463 (83.9\%) & $89(16.1 \%)$ & & $808(88.2 \%)$ & 108 (11.8\%) & \\
\hline \multirow[t]{2}{*}{ Gender } & Male & 387 (89.6\%) & $45(10.4 \%)$ & $0.000^{*}$ & 696 (90.2\%) & $76(9.8 \%)$ & $0.000^{*}$ \\
\hline & Female & 471 (79.8\%) & 119 (20.2\%) & & 872 (81.9\%) & 193 (18.1\%) & \\
\hline \multirow[t]{3}{*}{ Education } & Low & $531(81.7 \%)$ & $119(18.3 \%)$ & 0.306 & 794 (84.8\%) & $142(15.2 \%)$ & $0.033^{*}$ \\
\hline & Secondary & 315 (88\%) & $43(12 \%)$ & & 397 (85.2\%) & 69 (14.8\%) & \\
\hline & High & $11(84.6 \%)$ & $2(15.4 \%)$ & & $123(89.8 \%)$ & $14(10.2 \%)$ & \\
\hline \multirow[t]{6}{*}{ Marital Status } & Single & $238(87.5 \%)$ & $34(12.5 \%)$ & 0.051 & 725 (82.7\%) & $152(17.3 \%)$ & 0.322 \\
\hline & Married & 403 (81.7\%) & $90(18.3 \%)$ & & 431 (89\%) & $53(11 \%)$ & \\
\hline & Widowed & $34(81 \%)$ & $8(19 \%)$ & & $54(87.1 \%)$ & $8(12.9 \%)$ & \\
\hline & Divorced & $47(81 \%)$ & $11(19 \%)$ & & $64(85.3 \%)$ & $11(14.7 \%)$ & \\
\hline & Concubinage & $126(86.3 \%)$ & $20(13.7 \%)$ & & $257(86.8 \%)$ & 39 (13.2\%) & \\
\hline & Long-distance relationship & $9(90 \%)$ & $1(10 \%)$ & & $37(86 \%)$ & $6(14 \%)$ & \\
\hline \multirow[t]{6}{*}{ Ethnic background } & West Indians & $525(83.2 \%)$ & $106(16.8 \%)$ & $0.001^{*}$ & $368(86.8 \%)$ & $56(13.2 \%)$ & 0.277 \\
\hline & Creole & $83(87.4 \%)$ & $12(12.6 \%)$ & & $450(84.7 \%)$ & $81(15.3 \%)$ & \\
\hline & Maroon & $6(100 \%)$ & $0(0 \%)$ & & $165(76.4 \%)$ & $51(23.6 \%)$ & \\
\hline & Javanese & $148(81.8 \%)$ & $33(18.2 \%)$ & & $171(91.4 \%)$ & $16(8.6 \%)$ & \\
\hline & Mixed & $66(84.6 \%)$ & $12(15.4 \%)$ & & $344(87.1 \%)$ & $51(12.9 \%)$ & \\
\hline & Other & $28(96.6 \%)$ & $1(3.4 \%)$ & & $70(83.3 \%)$ & $14(16.7 \%)$ & \\
\hline \multirow[t]{7}{*}{ Daily activity } & Student/going to school & $81(86.2 \%)$ & $13(13.8 \%)$ & $0.001^{*}$ & $189(80.8 \%)$ & $45(19.2 \%)$ & $0.000^{*}$ \\
\hline & Working part-time & $59(86.8 \%)$ & $9(13.2 \%)$ & & $86(82.7 \%)$ & $18(17.3 \%)$ & \\
\hline & Working full-time & $293(87.5 \%$ & $42(12.5 \%)$ & & $826(88 \%)$ & $113(12 \%)$ & \\
\hline & Unemployed/jobseeker & $90(89.1 \%)$ & $11(10.9 \%)$ & & $92(82.9 \%)$ & $19(17.1 \%)$ & \\
\hline & Housewife/Houseman & $244(75.3 \%)$ & $80(24 / 7 \%)$ & & $217(79.2 \%)$ & $57(20.8 \%)$ & \\
\hline & Handyman & $42(93.3 \%)$ & $3(6.7 \%)$ & & $33(86.8 \%)$ & $5(13.2 \%)$ & \\
\hline & Retired & 38 (86.4\%) & $6(13.6 \%)$ & & 125 (91.2\%) & $12(8.8 \%)$ & \\
\hline
\end{tabular}


Table 4 Overview of the relationship between demographics and high risk of maladaptive thoughts about panic

\begin{tabular}{|c|c|c|c|c|c|c|c|}
\hline \multirow[t]{2}{*}{ Variable } & & \multicolumn{2}{|l|}{ Nickerie } & \multirow[t]{2}{*}{$P$} & \multicolumn{2}{|l|}{ Paramaribo } & \multirow[t]{2}{*}{$P$} \\
\hline & & Low & High & & Low & High & \\
\hline \multirow[t]{2}{*}{ Age } & $<40$ & $450(96.2 \%)$ & 18 (3.8\%) & 0.539 & 886 (96.2\%) & 35 (3.8\%) & 0.233 \\
\hline & $>40$ & $522(94.6 \%)$ & $30(5.4 \%)$ & & 876 (95.6\%) & $40(4.4 \%)$ & \\
\hline \multirow[t]{2}{*}{ Gender } & Male & 421 (97.9\%) & $9(2.1 \%)$ & $0.003^{*}$ & 753 (97.5\%) & $19(2.5 \%)$ & $0.001^{*}$ \\
\hline & Female & $551(93.4 \%)$ & 39 (5.5\%) & & 1009 (94.7\%) & $56(5.3 \%)$ & \\
\hline \multirow[t]{3}{*}{ Education } & Low & $613(96.9 \%)$ & $36(5.5 \%)$ & 0.051 & 888 (94.9\%) & $48(5.1 \%)$ & 0.184 \\
\hline & Secondary & 346 (96.9\%) & $11(3.1 \%)$ & & 448 (96.1\%) & $18(3.9 \%)$ & \\
\hline & High & $12(92.3 \%)$ & $1(7.7 \%)$ & & $136(99.3 \%)$ & $1(0.7 \%)$ & \\
\hline \multirow[t]{6}{*}{ Marital Status } & Single & $226(97.8 \%)$ & $6(2.2 \%)$ & 0.174 & 837 (95.4\%) & $40(4.6 \%)$ & $0.019 *$ \\
\hline & Married & 468 (95.3\%) & $23(4.7 \%)$ & & $473(97.7 \%)$ & $11(2.3 \%)$ & \\
\hline & Widowed & 37 (88.1\%) & $5(11.9 \%)$ & & $59(95.2 \%)$ & $3(4.8 \%)$ & \\
\hline & Divorced & 51 (89.5\%) & $6(10.5 \%)$ & & 69 (92\%) & $6(8 \%)$ & \\
\hline & Concubinage & $140(95.2 \%)$ & $7(4.8 \%)$ & & $283(95.6 \%)$ & $13(4.4 \%)$ & \\
\hline & Long-distance relationship & $9(90 \%)$ & $1(10 \%)$ & & $41(95.3 \%)$ & $2(4.7 \%)$ & \\
\hline \multirow[t]{6}{*}{ Ethnic background } & West Indians & $592(94 \%)$ & $38(6 \%)$ & $0.001^{*}$ & $404(95.3 \%)$ & $20(4.7 \%)$ & 0.205 \\
\hline & Creole & $93(97.9 \%)$ & $2(2.1 \%)$ & & $512(96.4 \%)$ & $19(3.6 \%)$ & \\
\hline & Maroon & $6(100 \%)$ & $0(0 \%)$ & & 199 (92.1\%) & $17(7.9 \%)$ & \\
\hline & Javanese & $147(97.2 \%)$ & $5(2.8 \%)$ & & $184(98.4 \%)$ & $3(1.6 \%)$ & \\
\hline & Mixed & 76 (96.2\%) & $3(3.8 \%)$ & & $380(96.2 \%)$ & $15(3.8 \%)$ & \\
\hline & Other & $29(100 \%)$ & $0(0 \%)$ & & $83(98.8 \%)$ & $1(1.2 \%)$ & \\
\hline \multirow[t]{7}{*}{ Daily activity } & Student/going to school & $92(97.9 \%)$ & $2(2.1 \%)$ & $0.000^{*}$ & $222(94.9 \%)$ & $12(5.1 \%)$ & $0.004^{*}$ \\
\hline & Working part-time & $68(100 \%)$ & $0(0 \%)$ & & $96(92.3 \%)$ & $8(7.7 \%)$ & \\
\hline & Working full-time & $319(95.8 \%)$ & $14(4.2 \%)$ & & $920(98 \%)$ & $19(2 \%)$ & \\
\hline & Unemployed/jobseeker & $98(97 \%)$ & $3(3 \%)$ & & $102(91.9 \%)$ & $9(8.1 \%)$ & \\
\hline & Housewife/Houseman & $296(91.4 \%)$ & $28(8.6 \%)$ & & $257(93.8 \%)$ & $17(6.2 \%)$ & \\
\hline & Handyman & $45(100 \%)$ & $0(0 \%)$ & & $31(81.6 \%)$ & $7(18.4 \%)$ & \\
\hline & Retired & $43(97.7 \%)$ & $1(2.3 \%)$ & & $134(97.8 \%)$ & $3(2.2 \%)$ & \\
\hline
\end{tabular}

Table 5 Treatment gap for men and women in Paramaribo and Nickerie

\begin{tabular}{|c|c|c|c|c|c|c|c|c|}
\hline \multirow[b]{3}{*}{ Risks for: } & \multicolumn{4}{|l|}{ Nickerie } & \multicolumn{4}{|c|}{ Paramaribo } \\
\hline & \multicolumn{2}{|c|}{ Men $(N=429)$} & \multicolumn{2}{|c|}{ Women $(N=583)$} & \multicolumn{2}{|c|}{$\operatorname{Men}(N=772)$} & \multicolumn{2}{|c|}{ Women $(N-1065)$} \\
\hline & $\begin{array}{l}\text { Total num- } \\
\text { ber with a } \\
\text { risk }\end{array}$ & Not in treatment & $\begin{array}{l}\text { Total num- } \\
\text { ber with a } \\
\text { risk }\end{array}$ & Not in treatment & $\begin{array}{l}\text { Total num- } \\
\text { ber with a } \\
\text { risk }\end{array}$ & Not in treatment & $\begin{array}{l}\text { Total num- } \\
\text { ber with a } \\
\text { risk }\end{array}$ & Not in ttreatment \\
\hline $\begin{array}{l}\text { Major Depression } \\
\text { risk (CES-D) }\end{array}$ & 68 & $86.8 \%$ & 119 & $93.3 \%$ & 89 & $91 \%$ & 207 & $89.9 \%$ \\
\hline $\begin{array}{l}\text { General Anxiety } \\
\text { Risk (GAD-7) }\end{array}$ & 7 & $100 \%$ & 31 & $90.3 \%$ & 20 & $85 \%$ & 46 & $78.3 \%$ \\
\hline $\begin{array}{l}\text { High Maladaptive } \\
\text { thoughts (ACQ) }\end{array}$ & 9 & $88.9 \%$ & 38 & $92.1 \%$ & 19 & $78.9 \%$ & 56 & $80.4 \%$ \\
\hline $\begin{array}{l}\text { High anxiety about } \\
\text { body sensations } \\
\text { (BSQ) }\end{array}$ & 44 & $97.7 \%$ & 118 & $93.2 \%$ & 76 & $94.7 \%$ & 193 & $94.8 \%$ \\
\hline
\end{tabular}

\section{Discussion}

In summary, we found an $18 \%$ risk of depression in Nickerie and $16 \%$ in Paramaribo. The prevalence of the risk of general anxiety disorder was $3.8 \%$ in Nickerie and 3.6\% in Paramaribo but the risk of women developing these disorders was higher in both regions. In addition, differences were found relating to civil status, ethnicity and education level. Moreover, women were more likely to 
Table 6 Odd's ratio with 95\% confidence interval for the risks in Nickerie compared with Paramaribo

Odd Lower Cl Upper Cl

\begin{tabular}{llll}
\hline Risks for: & & & \\
Major Depression risk (CES-D) & 1.18 & 0.97 & 1.45 \\
General Anxiety Risk (GAD-7) & 1.06 & 0.71 & 1.59 \\
High Maladaptive thoughts (ACQ) & 1.11 & 0.90 & 1.38 \\
$\begin{array}{l}\text { High anxiety about body sensations } \\
\text { (BSQ) }\end{array}$ & 1.16 & 0.80 & 1.68 \\
\hline
\end{tabular}

develop somatic problems related to these disorders. We found a treatment gap of between 78 and $100 \%$ for the disorders studied.

In both areas, the risk of depression was significantly higher for women than men. We saw probable depression in about $20 \%$ of women and in $12 \%$ of men. In particular, women with a low level of education, widows, divorced and unemployed women had a higher risk. In low-income and developing countries, depression among women is associated with conditions that include limited economic and educational opportunities, economic difficulties, restricted autonomy, forced marriages, domestic violence, and low levels of family support [38].

The results of the current study indicate that probable depression is more prevalent in women (20\%) than men $(12 \%)$, the exact cause of this is unclear and worth further research. One study has found that gender differences relating to depression can be explained by the different social roles assigned by society to men and women [39]. Gender roles are defined in line with a society's beliefs about differences between the sexes [40]. According to $\mathrm{Yu}$ [41], gender differences can be attributed to gender inequality to a significant extent. Psychosocial events such as coping style and the perceived stigma of mental illness all contribute to the increased vulnerability of women to depression as well [42]. These factors may have contributed to the higher percentage among the women of this study.

Turning to the stigma of mental illness: men tend to conform to traditional masculine norms, which are correlated with less help-seeking behaviour and more negative attitudes towards seeking psychological treatments [43]. Due to these traditional masculine norms, men who experience symptoms of depression may not actively seek help, the prevalence numbers among these men may hence go unreported. This could be the case in our study and could be an explanation for the higher depression and anxiety rates are Surinamese women than men.

The prevalence rates for anxiety (with the exception of high anxiety about body sensations) are much lower than the prevalence rates for depression in Nickerie and Paramaribo, but they are consistent with another study [44], a meta-analysis that found a life-time prevalence rate for GAF of $4.1 \%$ in women and $2.1 \%$ in men. We did find high percentages of respondents with high anxiety about body sensations. This is related to the high percentages of respondents with a likely depression.

The treatment gap of $90 \%$ on average is quite high but comparable with other LMICs. Improving treatment availability by establishing regional clinics could reduce this percentage to acceptable levels. We found that levels of possible depression are highest among West Indians.

In recent years, rural areas have reported higher suicide rates than urban areas worldwide and agricultural activity is a key characteristic of many rural areas [52]. Research shows that suicide rates in Nickerie are higher than those in Paramaribo (68 suicides from 2000-2003 in Nickerie) [32]. A possible explanation would be that depression (often preceding or associated with suicide) is more frequent in Nickerie than in Paramaribo. However, the current study shows that depression is as prevalent in Paramaribo as in Nickerie and further research may therefore seem beneficial.

\section{Conclusions}

As the results indicate there is a risk of depression in both regions and that there is a treatment gap of $90 \%$. Furthermore it has been concluded that probable depression is more prevalent in women $(20 \%)$ than men $(12 \%)$ and West-indians. Improving treatment availability by establishing regional clinics could remedy the high treatment gap.

\section{Abbreviations}

ABS: Algemeen Bureau voor de Statistiek (general Bureau of statistics); ACQ: The Agoraphobic Cognitions Questionnaire; BSQ: The Body Sensations

Questionnaire; CES-D: The Center for Epidemiological Studies-Depression; DC: District Commissioners; DSM-5: The Diagnostic and Statistical Manual of Mental Disorders; GAD-7: The Generalized Anxiety Disorder 7; LMICs: Low-middleincome countries; OR: Odds Ratio; PCS: The center for psychiatry in Suriname; WHO: World Health Organization.

\section{Acknowledgements}

Not applicable.

\section{Authors' contributions}

RJ co-designed the study, supervised the data acquisition in Nickerie and drafted the manuscript. EdB validated the screeners and methods and critically reviewed the manuscript. KE collected data, prepared data for presentation, assisted in drafting and critically reviewed the manuscript. $\mathrm{MB}$ processed the data, drew preliminary conclusions, and critically reviewed the manuscript. RD co-designed the study, assisted in the collection of data, and critically reviewed the manuscript. JP finalized the statistical calculations and critically reviewed the manuscript. VL supervised the data collection in Paramaribo, reviewed the acquired data and preliminary conclusions and critically reviewed the manuscript. RB reviewed the study design, assisted in data processing, collected the literature, assisted in drafting, and critically reviewed the manuscript. JD supervised the whole study, evaluated and reprocessed the data, presented the data structure and critically reviewed the manuscript. The author(s) read and approved the final manuscript. 


\section{Funding}

The study was funded through a twinning facility by the Dutch Ministry of Foreign Affairs under the name of "Dwarkasing R, De Jonge M. Onderzoek naar alcoholgebruik, angst en depressieve klachten in Suriname, en aanbieden van zorg op maat en geïndiceerde e-mental health. Paramaribo, Amsterdam: 2014" project number UTSN2/1-Z-105-G. The funding body had no role in the design of the study or in the collection, analysis and interpretation of data or the writing of the manuscript.

\section{Availability of data and materials}

The data that support the findings of this study are available from the Center of Psychiatry in Suriname (PCS) but restrictions apply to the availability of these data, which were used under license for the current study and so are not publicly available. Data are, however, available from the authors upon reasonable request and subject to permission from the Center of Psychiatry in Suriname.

\section{Declarations}

\section{Ethics approval and consent to participate}

The study design and the collection of data were approved by the Ethics Committee on Human Scientific Research (CMWO) of the Ministry of Health of Suriname. All participants or their parental representatives gave informed consent for participation. In case a participant was illiterate, written consent was presented to a representative of the participant who detailed the content to that specific participant and then finalized with a signature. All methods applied were in complete accordance with the national and international laws and rules and the Declaration of Helsinki.

\section{Consent for publication}

Not applicable.

\section{Competing interests}

The authors declare that they have no competing interests.

\section{Author details}

${ }^{1}$ Center for Psychiatry in Suriname and Faculty of Social Science, Anton de Kom University of Suriname, Letitia Vriesdelaan 1 - 3, Paramaribo, Suriname. ${ }^{2}$ Research Department, Arkin Mental Health Institute, Amsterdam, The Netherlands. ${ }^{3}$ Department of Clinical Psychology, Faculty of Social Sciences, Leiden University, Leiden, The Netherlands. ${ }^{4}$ Center for Psychiatry in Suriname and Department of Psychiatry, Anton de Kom University of Suriname, Paramaribo, Suriname. ${ }^{5}$ Department of Physiology, Faculty of Medicine, Anton de Kom University of Suriname, Paramaribo, Suriname. ${ }^{6}$ Department of Clinical Psychology, VU University Amsterdam, Amsterdam, The Netherlands.

Received: 16 May 2021 Accepted: 21 December 2021

Published online: 08 January 2022

\section{References}

1. American Psychiatric Association. Diagnostic and statistical manual of mental disorders (DSM-5 ${ }^{\circledR}$ ): American Psychiatric Pub; 2013.

2. Marcus M, Yasamy MT, Van Van Ommeren M, Chisholm D, Saxena S. Depression: A global public health concern; 2012.

3. Alqahtani A. Prevention of Depression: A Review of Literature. J Depress Anxiety. 2017;6:292.

4. England MJ, Sim LJ. Depression in parents, parenting, and children: Opportunities to improve identification, treatment, and prevention. In: Depression in Parents, Parenting, and Children: Opportunities to Improve Identification, Treatment, and Prevention: National Academies Press; 2009. p. 1-488. [cited 2021 Jan 22]. Available from: https://www.ncbi.nlm. nih.gov/books/NBK215117/.

5. Bromet E, Andrade LH, Hwang I, Sampson NA, Alonso J, De Girolamo G, et al. Cross-national epidemiology of DSM-IV major depressive episode. BMC Med. 2011;9(1):90.

6. Gorman JM. Comorbid depression and anxiety spectrum disorders. Depress Anxiety. 1996;4(4):160-8.

7. Tiller JWG. Depression and anxiety. Med J Aust. 2013;199(6):S28-31.
8. Simpson HB, Neria Y, Lewis-Fernández R, Schneier F. Anxiety disorders: Theory, research and clinical perspectives: Cambridge University Press; 2010.

9. Takahashi Y. Depression and suicide. Japan Med Assoc J. 2001:44(8):359-63.

10. Kanwar A, Malik S, Prokop LJ, Sim LA, Feldstein D, Wang Z, et al. The association between anxiety disorders and suicidal behaviors: A systematic review and meta-analysis. Depress Anxiety. 2013;30(10):917-29.

11. Wells KB, Stewart A, Hays RD, Burnam MA, Rogers W, Daniels M, et al. The Functioning and Well-being of Depressed Patients: Results From the Medical Outcomes Study. JAMA. 1989;262(7):914-9. https://doi.org/10. 1001/jama.1989.03430070062031.

12. Mendlowicz MV, Stein MB. Quality of life in individuals with anxiety disorders. Am J Psychiatry. 2000;157(5):669-82.

13. Wells KB, Sherbourne CD. Functioning and Utility for Current Health of Patients With Depression or Chronic Medical Conditions in Managed, Primary Care Practices. Arch Gen Psychiatry. 1999;56(10):897-904. https:// doi.org/10.1001/archpsyc.56.10.897.

14. Brenes GA, Penninx BWJH, Judd PH, Rockwell E, Sewell DD, Wetherell JL. Anxiety, depression and disability across the lifespan. Aging Ment Health. 2008;12(1):158-63. https://doi.org/10.1080/13607860601124115.

15. Kessler RC, Frank RG. The impact of psychiatric disorders on work loss days. Psychol Med [Internet]. 1997;27(4):861-73 Available from: https:// www.cambridge.org/core/article/impact-of-psychiatric-disorders-onwork-loss-days/F561230BCFEC07EF4C737DF746B98727.

16. Brenes GA, Kritchevsky SB, Mehta KM, Yaffe K, Simonsick EM, Ayonayon $\mathrm{HN}$, et al. Scared to Death: Results From the Health, Aging, and Body Composition Study. Am J Geriatr Psychiatry [Internet]. 2007;15(3):262-5 Available from: https://www.sciencedirect.com/science/article/pii/S1064 748112604448

17. Purtle J, Nelson KL, Yang Y, Langellier B, Stankov I, Roux AVD. Urban-rural differences in older adult depression: A systematic review and metaanalysis of comparative studies. Am J Prev Med. 2019;56(4):603-13.

18. Vigo D, Thornicroft G, Atun R. Estimating the true global burden of mental illness. Lancet Psychiatry. 2016;3(2):171-8 [cited 2021 Nov 16]. Available from: http://www.thelancet.com/article/S2215036615005052/ fulltext.

19. James SL, Abate D, Abate KH, Abay SM, Abbafati C, Abbasi N, et al. Global, regional, and national incidence, prevalence, and years lived with disability for 354 Diseases and Injuries for 195 countries and territories, 1990-2017: A systematic analysis for the Global Burden of Disease Study 2017. Lancet. 2018:392(10159):1789-858 [cited 2021 Nov 16]. Available from: http://www.thelancet.com/article/S0140673618322797/fulltext.

20. Gruebner O, Rapp MA, Adli M, Kluge U, Galea S, Heinz A. Risiko für psychische Erkrankungen in Städten; 2017.

21. Baxter AJ, Scott KM, Vos T, Whiteford HA. Global prevalence of anxiety disorders: a systematic review and meta-regression. Psychol Med. 2013;43(5):897.

22. Graafsma T, Kerkhof A, Gibson D, Badloe R, Van de Beek LM. High rates of suicide and attempted suicide using pesticides in Nickerie, Suriname, South America. Crisis. 2006;27(2):77-81.

23. Astbury J. Gender disparities in mental health; 2001.

24. Tsai JL, Chentsova-Dutton Y. Understanding depression across cultures. In: Gotlib IH, Hammen C, editors. Handbook of Depression. New York: The Guilford Press; 2002. p. 467-91.

25. Dwarkasing R, De Jonge M. Onderzoek naar alcoholgebruik, angst en depressieve klachten in Suriname, en aanbieden van zorg op maat en geïndiceerde e-mental health. Amsterdam: Paramaribo; 2014.

26. Jadnanansing R, Blankers M, Dwarkasing R, Etwaroo K, Lumsden V, Dekker $J$, et al. Prevalence of Substance Use Disorders in an Urban and a Rural Area in Suriname. Trop Med Health. 2021;49:12

27. Radloff LS. The CES-D scale: A self-report depression scale for research in the general population. Appl Psychol Meas. 1977;1(3):385-401.

28. Brown CR, Hambleton IR, Sobers-Grannum N, Hercules SM, Unwin N, Nigel Harris E, et al. Social determinants of depression and suicidal behaviour in the Caribbean: A systematic review. BMC Public Health. 2017;17(1):1-11 [cited 2021 Nov 14]. Available from: https://link.springer. com/articles/10.1186/s12889-017-4371-z.

29. Himle JA, Baser RE, Taylor RJ, Campbell RD, Jackson JS. Anxiety disorders among African Americans, blacks of Caribbean descent, and non-Hispanic whites in the United States. J Anxiety Disord [Internet]. 
2009;23(5):578-90 Available from: https://www.sciencedirect.com/scien ce/article/pii/S0887618509000036.

30. "Algemeen Bureau voor de Statistiek in Suriname." Resultaten achtste (8e) volks - en woningtelling in suriname | Algemeen Bureau voor de Statistiek in Suriname [Internet]. [cited 2021 Jan 22]. Available from: https://statistics-suriname.org/nl/resultaten-achtste-8e-volks-en-wonin gtelling-in-suriname/

31. Löwe B, Decker O, Müller S, Brähler E, Schell berg D, Herzog W, et al. Validation and standardization of the Generalized Anxiety Disorder Screener (GAD-7) in the general population. Med Care. 2008;46:266-74.

32. Beekman ATF, Van Limbeek J, Deeg DJH, Wouters L, Van Tilburg W. Een screeningsinstrument voor depressie bij ouderen in de algemene bevolking: de bruikbaarheid van de Center for Epidemiologic Studies Depression Scale (CES-D). Tijdschr Gerontol Geriatr. 1994;25(3):95-103.

33. Beekman ATF, Deeg DJH, Van Limbeek J, Braam AW, De Vries MZ. Van Tilburg W. Brief communication.: criterion validity of the Center for Epidemiologic Studies Depression scale (CES-D): results from a communitybased sample of older subjects in the Netherlands. Psychol Med. 1997;27(1):231-5.

34. Spitzer RL, Kroenke K, Williams JBW, Löwe B. A brief measure for assessing generalized anxiety disorder: the GAD-7. Arch Intern Med. 2006;166(10):1092-7.

35. Chambless DL, Caputo GC, Bright P, Gallagher R. Assessment of fear of fear in agoraphobics: the body sensations questionnaire and the agoraphobic cognitions questionnaire. J Consult Clin Psychol. 1984;52(6):1090.

36. Arrindell WA. The fear of fear concept: Stability, retest artefact and predictive power. Behav Res Ther. 1993;31 (2):139-48 Available from: http:// www.sciencedirect.com/science/article/pii/0005796793900653.

37. Bouman TK. Kort instrumenteel: De Agoraphobic Cognition Questionnaire (ACQ). Gedragstherapie. 1995;28:301-4.

38. Bhattacharya A, Camacho D, Kimberly LL, Lukens EP. Women's experiences and perceptions of depression in India: A metaethnography. Qual Health Res. 2019;29(1):80-95.

39. González G, Vives A. Work status, financial stress, family problems, and gender differences in the prevalence of depression in Chile. Ann Work Expo Heal. 2019;63(3):359-70.

40. Blackstone AM, Miller JR, Lerner RM, Schiamberg Santa Barbara LB. Gender Roles and Society. 2003 [cited 2021 Jan 22]. Available from: https:// digitalcommons.library.umaine.edu/soc_facpub

41. Yu S. Uncovering the hidden impacts of inequality on mental health: a global study. Transl Psychiatry. 2018;8(1):1-10.

42. Kulesza M, Raguram R, Rao D. Perceived mental health related stigma, gender, and depressive symptom severity in a psychiatric facility in South India. Asian J Psychiatr. 2014;9:73-7.

43. Levant RF, Wimer DJ, Williams CM. An evaluation of the Health Behavior Inventory-20 (HBI-20) and its relationships to masculinity and attitudes towards seeking psychological help among college men. Psychol Men Masculinity. 2011;12(1):26.

44. McLean CP, Asnaani A, Litz BT, Hofmann SG. Gender differences in anxiety disorders: prevalence, course of illness, comorbidity and burden of illness. J Psychiatr Res. 2011;45(8):1027-35.

\section{Publisher's Note}

Springer Nature remains neutral with regard to jurisdictional claims in published maps and institutional affiliations.

Ready to submit your research? Choose BMC and benefit from:

- fast, convenient online submission

- thorough peer review by experienced researchers in your field

- rapid publication on acceptance

- support for research data, including large and complex data types

- gold Open Access which fosters wider collaboration and increased citations

- maximum visibility for your research: over $100 \mathrm{M}$ website views per year

At $\mathrm{BMC}$, research is always in progress.

Learn more biomedcentral.com/submissions 